\title{
Intravenous fluid therapy: a randomized controlled trial to investigate the effectiveness of the $\mathrm{IV}^{2 \mathrm{TM}}$ flow medical device
}

\author{
Nesta Fraser MBChB, MPharmMed, \\ Department of Pharmacology, University of Pretoria, Pretoria, Gauteng, South Africa \\ Jacques R Snyman MD, MBChB, MPharmMed, \\ Department of Pharmacology, University of Pretoria, Pretoria, Gauteng, South Africa \\ Francois Wessels MSc, MTh \\ Outcomes Consultant, Monumentpark, Pretoria, South Africa \\ George Nel BSc, MSc \\ Outcomes Consultant, Monumentpark, Pretoria, South Africa
}

\section{Abstract}

Objectives. To investigate the hypothetical benefits of the IV ${ }^{2 T M}$ flow medical device.

Background. Intravenous fluid administration is a standard hospital procedure with assumed inadequacies. The IV-Event Study [Fraser N, Nel G, Snyman J \& Wessels F (2004) IV-EVENT Study: Intravenous Infusion Therapy - Management and Adverse Events. Data on File: Varori International (Pty) Ltd., Centurion, South Africa] quantified these inadequacies; The 'Stargait' intervention trial investigated the effectiveness and possible cost-benefit of the IV ${ }^{2 T M}$ flow. The $I^{2 T M}$ flow is intended for routine use with gravitational intravenous infusion sets. The IV ${ }^{2 T M}$ flow should reduce the incidence rate of adverse events and maintain a set flow rate.

Method. Nursing staff assisted by study assessors captured relevant data. Consented patients were enrolled for the period of their prescribed infusions.

Intervention. The Stargait Trial compared the treatment group (standard gravitational sets with the IV ${ }^{2 T M}$ flow) with the control group (standard gravitational infusion sets without IV ${ }^{2 T M}$ flow). The difference in observed events and the cost benefit derived from this were measured.

Results. A total of 2387 drip hours were observed in 52 patients. The adverse event rates were: Control group (without IV ${ }^{2 \mathrm{TM}}$ flow) $33.8 \%$. The treatment group (IV ${ }^{2 \mathrm{TM}}$ flow) $15 \cdot 4 \%$. This $55 \%$ reduction is statistically significant $(p=0.0069)$. Adverse event related monetary wastage (labour and consumables) is reduced by $76 \%$ for infusion bags in the intervention group (with IV ${ }^{2 \mathrm{TM}}$ flow). There was a significant difference between the treatment group and control group as far as deviation in flow rate was concerned $(p=0.00818)$. The mean deviation of the $\mathrm{IV}^{2 \mathrm{TM}}$ flow group was just more than $5 \mathrm{ml}$ per hour. The standard line group had a mean deviation of more than $30 \mathrm{ml}$ per hour.

Conclusion. Gravitational intravenous therapy compromises quality of patient care. The Stargait Trial has proven the care-effectiveness and cost-effectiveness of the IV ${ }^{2 T M}$ flow.

Relevance to clinical practice. The $\mathrm{IV}^{2 \mathrm{TM}}$ flow improves quality of patient care and reduces associated wastage. 


\section{Introduction}

New methods and devices for administration of intravenous medications are entering the market. Providers are forced to re-evaluate current methods of delivering services to patients. This decision-making process must include an evaluation of the costs associated with each system as well as an evaluation of system characteristics (Fraser et al. 2004).

Physicians are required, on a daily basis, to write orders for administration of intravenous fluid and must be able to justify their choices on clinical grounds (Birdwell 1993). Management of prescribed infusion therapy then becomes the responsibility of attending nursing professionals. Limitations inherent to standard gravitational intravenous infusion (IV) sets routinely used, combined with pressure on nursing time, leads to specific complications that have a negative impact on patient care and resource use (nursing time and consumables).

Deviations in actual vs. prescribed flow rates occur routinely, even if calibration is performed correctly. Flow of intravenous fluid through an IV-line is a gravitational process driven by the fluid volume (pressure) in the container, which constantly declines while the container runs in. This hydraulic mechanism of driving fluid leads to variations in set flow rates. So-called 'creeping of the roller-clamp wheel' further exacerbates this inherent deviation (Makkink 2001).

The second set of complications relates to adverse events (AE). Adverse events (e.g. air emboli, reverse blood flow, clots forming in the line, fluid in tissue, phlebitis, needle dislodge and repriming) can manifest alone or in combination.

The IV-Event Study collected time-and-motion data for the gravitational IV-sets currently in use. This exploratory observational study quantified the negative impact of intravenous fluid administration on patient care and resources (Fraser et al. 2004). The IV-Event Study established two areas of significance. Firstly, there was a clinical significant $(30 \%)$ variation in actual vs. prescribed flow rates during IV-fluid administration.

Only $12 \%$ of the observed containers were infused within a $10 \%$ deviation $(72 \%$ under infused and $22 \%$ over infused). Secondly, AEs were experienced by $53 \%$ of patients, with an incidence rate of $25 \%$ (one in four bags) (Fraser et al. 2004).

The IV-Event Study was motivated by a phase 1 clinical trial, the Clinical validation trial of the $I V^{2 \mathrm{TM}}$ flow.

This study established an average deviation in flow rate of $35.2 \%$ (Ker 2002) (using standard gravitational infusion sets with a dial type rate control mechanism). The same study confirmed flow rates with $\mathrm{IV}^{2 \mathrm{TM}}$ flow (in line with standard gravitational infusion sets with a dial type rate control mechanism) are accurate within $10 \%(8.4 \%)$ of the calibrated flow rate (Ker 2002). This compares favourably with the standard set by electronic infusion pumps (5\% deviation) (Ker 2002) and represents a major technological advance for the gravitational infusion industry. 
The IV ${ }^{2 T M}$ flow (IVF) medical device was designed to address the inherent shortcomings of standard gravitational IV-sets.

Hypothetically the IVF device closes the IV-line when a container runs empty (See Fig. 1). The line remains free of air and the fluid column is maintained. Reverse blood flow should be limited, formation of blood clots reduced and air emboli prevented. Inclusion of the IVF maintains the set flow rate through creating a new hydraulic head reference point and keeping it constant for the duration of the infusion.

The Stargait Trial aimed to quantify possible superiority of standard gravitational sets equipped with the IVF (to those without the IVF).

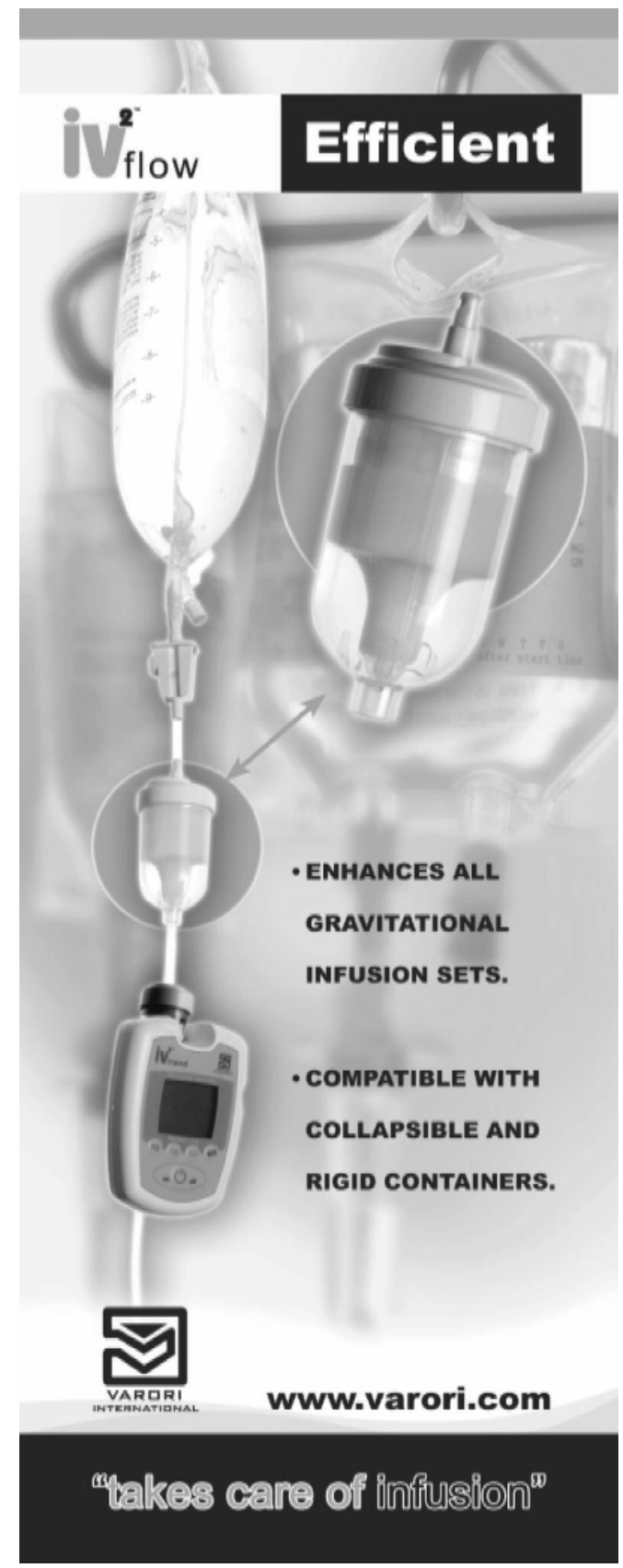

Figure 1 The IV ${ }^{2 T M}$ flow medical device illustrated in a typical clinical environment. 


\section{Background}

Flow rate accuracy is a prerequisite for administration of parenteral fluid. The intention of prescribing physicians is for patients to receive IV fluids as per script for specific clinical indications.

If IV-sets are calibrated accurately and it can be assumed that flow rates will be maintained by the system, a high level of agreement between actual and prescribed flow rates will emerge.

\section{Physiological and pathological factors relevant to intravenous fluid therapy to be emphasized are the following:}

The body has a powerful defence against water deficit, but very little against water excess. An increase in serum sodium concentration of $4-5 \mathrm{mmol} / \mathrm{l}$ above the usual normal value is a powerful stimulus for thirst.

A conscious patient will demand or drink water until the thirst subsides. On the other hand, hyponatremia does not create feelings of aversion to water. In other words, insufficient water intake will not remain uncorrected in a conscious patient, whereas no effective defence mechanism exists to prevent hyponatremia and fluid overload (Shafiee et al. 2003).

Fluid overload can lead to pulmonary congestion, and hyponatremia; the commonest electrolyte abnormality in hospitalized patients (Larson \& Hargiss 1984). If the plasma sodium concentration declines to less than $120 \mathrm{mmol} / \mathrm{l}$ in 48 hours, brain swelling may result in herniation, with devastating consequences.

The impact of adverse events on quality of patient care and resource wastage should not be underestimated:

- Containers running empty cause air in line, reverse blood flow and blood clot formation. Bag replacements create the potential for air embolism

- In the IV-Event Study $53 \%$ of subjects experienced one or more adverse event;

- The financial relevance is reflected in the wastage per 24 hours of infusion. Extrapolated to the millions of hours infused per annum, this is an unexplored cost containment measure;

- The total wastage per 24 hours of infusion (as per IV-Event Study) is R25.19 ( $R=$ ZAR = South African Rand 6.6289 to the US\$ on 31 August 2004), of which $88 \%$ can be attributed to consumables and $12 \%$ to labour. 


\section{Stargait Trial}

\section{Patients and methods}

\section{Patients}

Patients of 18 years and older, managed in a general ward with maintenance IV-fluid without an electronic infusion pump, were recruited into the study. The study was approved by the Research Ethics Committee of the Faculty of Health Science, University of Pretoria and all volunteers signed informed consent.

Study design and treatment

This was a randomized unblinded clinical trial consisting of four study arms:

Control - Roller clamp flow regulator without IVF [STD/RC]

Active - Roller clamp flow regulator with IVF [IVF/RC]

Control - Dial Type regulator without IVF [STD/DF]

Active - Dial Type regulator with IVF [IVF/DF]

Both the Active and Control groups received the same IV-lines (supplied by Varori International (Pty) Ltd., Centurion, South Africa). The medical device (IVF) was incorporated into the main line as well as the added line of the standard gravitational infusion sets of the patients in the treatment (active) groups. Enrolment in the study was in a general ward once a new (full) container was initiated.

\section{Evaluation of patients}

The nursing personnel routinely managing the IV-sets captured the study data on the log sheets with assistance from study assessors (SA) if required. Training was performed to ensure correct completion of the log sheets, correct calibration techniques as well as ability to manage the study device with success. The correct use of the IVF device was demonstrated during the trial. The attending SA assisted the nursing professional in changing the infusion lines of the consented patients and at initiation of the new vaculitre ensured that calibration was correctly performed. A note was made of the number of manual adjustments to drip rates in each arm of the study. 
Statistics and pharmacoeconomics

The primary variable for this study was efficiency as indicated by the reduction in AEs. This is a categorical variable. Secondary variables were flow rate accuracy and cost-implications (AE related wastage). The sample size calculation was based on the proportions assessed in the exploratory IV-Event Study (Fraser et al. 2004).

Two proportions were assessed: the adverse event rate and the proportion of the bags infused within acceptable flow specifications. A significance level of $5 \%$ is observed while the power of the test is maintained at $80 \%$. The roller clamp flow regulator was used in the treatment arms observed for the primary variable.

The pharmacoeconomic analysis was conducted from a provider's perspective. A costeffectiveness analysis (CEA) will assist the provider in determining whether the benefits of implementing the routine use of the IVF in IV-sets will exceed cost.

Certain assumptions, based on good clinical practice, limit the amount of data to be captured. These assumptions apply to labour time spent and consumables used. [Extracted from the IVEvent Study (Fraser et al. 2004)]

\section{Results}

\section{Patients and demographics}

The demographic analysis of the enrolled patients indicated an even distribution of baseline characteristics. Over a period of nine days 52 patients were enrolled and 202 vaculitres observed (2387 drip hours).

\section{Primary endpoint}

The primary study endpoint of reduction in AEs was based on the roller clamp groups (38 patients with 146 main line IV-bags).

A chi-square analysis assesses the relationship between device type and the occurrence of AEs. The number of AEs generates frequency data and therefore a Chi-square analysis is indicated. The $55 \%$ reduction in AEs was an improvement on the $50 \%$ anticipated reduction. In the IVF/RC group, the frequency of AEs was $15.4 \%$ compared with the $33.8 \%$ in the STD/RC group. Fig. 2 shows the various $A E$ manifestations noted for the Roller Clamp arms (Table 1). 


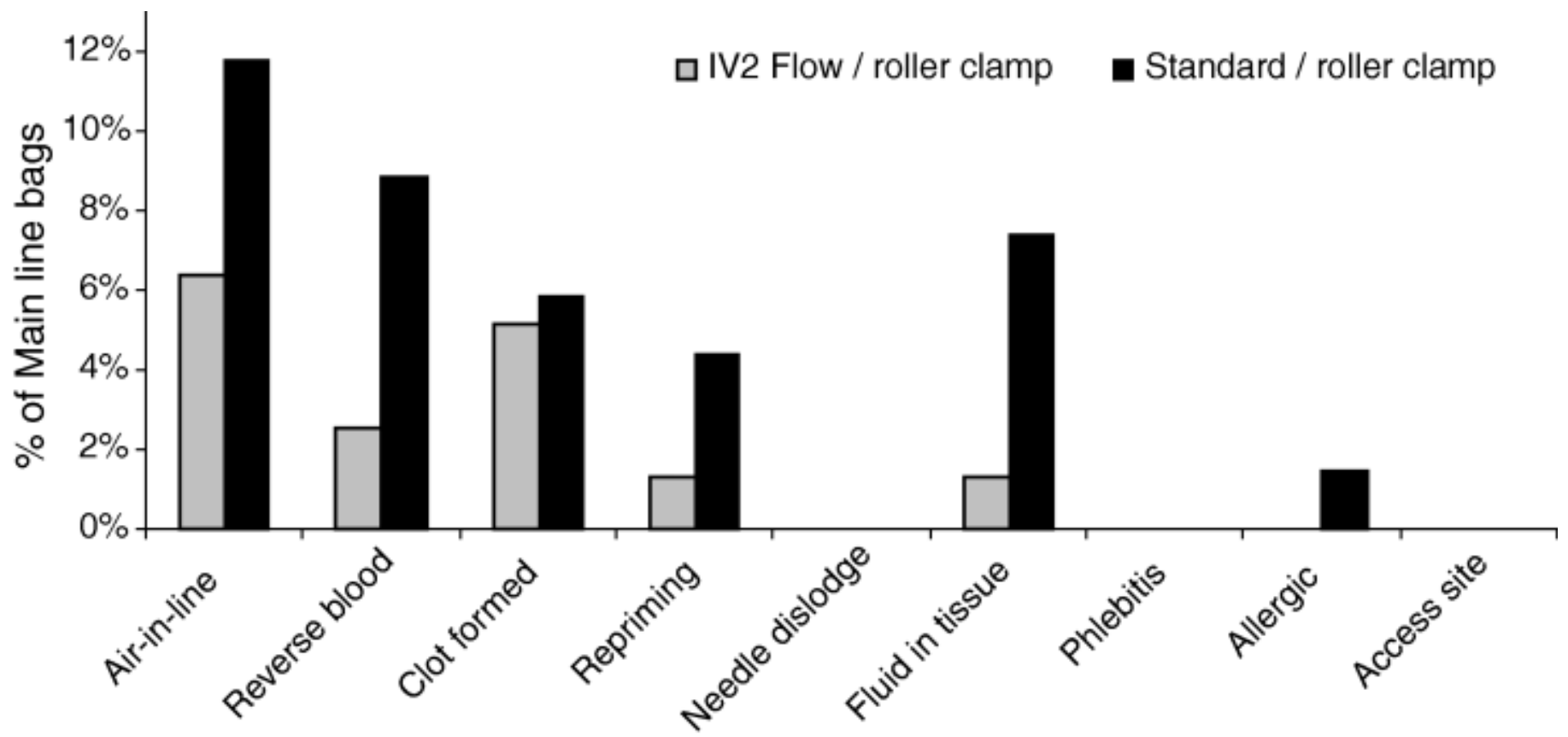

Figure $2 \mathrm{AE}$ manifestations $\mathrm{s}$ a persentage of main line bags (roller clamp groups).

\begin{tabular}{|c|c|c|c|c|}
\hline & $\begin{array}{l}\text { Main line bags } \\
\text { observed }\end{array}$ & $\begin{array}{c}\text { Main line bags with } \\
\text { AEs }\end{array}$ & $\begin{array}{c}\text { Number of } \\
\text { AEs }\end{array}$ & $\begin{array}{c}\text { Frequency of } \\
\text { AEs }\end{array}$ \\
\hline $\begin{array}{l}\text { Standard/roller } \\
\text { clamp }\end{array}$ & 68 & 20 & 23 & $33 \cdot 8 \%$ \\
\hline IV²low/roller clamp $^{2}$ & 78 & 9 & 12 & $15 \cdot 4 \%$ * \\
\hline
\end{tabular}

Table 1 Frequency of adverse events (AEs)

\begin{tabular}{|c|c|c|c|c|}
\hline & $n$ & Deviation (ml per hour) & SD & SE \\
\hline Standard/roller clamp & 68 & $-29 \cdot 7$ & $50 \cdot 9$ & $6 \cdot 2^{*}$ \\
\hline IVF/Roller clamp & 78 & -5 & $60 \cdot 6$ & $6 \cdot 9$ \\
\hline Standard/dial-a-flow & 38 & -36 & $35 \cdot 5$ & $5 \cdot 8$ \\
\hline IVF/dial-a-flow & 14 & $-7 \cdot 2$ & 75.9 & $20 \cdot 3$ \\
\hline
\end{tabular}

Table 2 Mean flow rate accuracy (vs. prescribed flow rate) 


\section{Secondary endpoint}

The deviation in flow rate as calculated by the difference between prescribed and observed flow rates, was analysed by means of analyses of variance (ANOVA) and $t$-tests. There was a significant difference between IVF lines and STD lines as far as deviation in flow rate was concerned $(p=0.00818)$. Results of a $t$-test of flow rate deviations strengthened this observation $(p=0.000699)$.

As is evident from Table 2, the magnitude of mean deviations in $\mathrm{ml}$ per hour was -5 (IVF/RC) and $-7 \cdot 2$ (IVF/DF) to $-36 \cdot 0$ (STD/DF) and $-29 \cdot 7$ (STD/RC).

These mean deviations are point estimates (based on deviation from prescribed flow rate). It is therefore clear that the mean deviations associated with IVF-arms are significantly lower than that for the standard IV line.

\begin{tabular}{|c|c|c|c|c|}
\hline & $\begin{array}{c}\mathrm{AE} \\
\text { rate }\end{array}$ & $\begin{array}{c}\text { Frequency of } \\
\text { AE's }\end{array}$ & $\begin{array}{c}\text { Ave cost per } \\
\mathrm{AE}\end{array}$ & $\begin{array}{c}\text { Total wastage per } 1000 \text { IV- } \\
\text { bags }\end{array}$ \\
\hline Standard/roller clamp & $34 \%$ & 338 & ${ }^{*} \mathrm{R} 47 \cdot 12$ & *R15 939 \\
\hline $\begin{array}{l}\text { IV-flow (IVF)/roller } \\
\text { clamp }\end{array}$ & $15 \%$ & 154 & ${ }^{*} \mathrm{R} 24.65$ & ${ }^{*} \mathrm{R} 3792$ \\
\hline Difference & $-18 \%$ & -184 & ${ }^{*} \mathrm{R}-22 \cdot 47$ & ${ }^{*} \mathrm{R}-12147$ \\
\hline Variance & $-55 \%$ & $-55 \%$ & $-48 \%$ & $-76 \%$ \\
\hline
\end{tabular}

Table 3 Cost of adverse event (AE) related wastage with infusion of 1000 main line bags

\begin{tabular}{|l|l|l|}
\hline \multicolumn{1}{|c|}{ Days infused } & \multicolumn{1}{|c|}{ Number of bags } & \multicolumn{1}{|c|}{ Break-even } \\
\hline $0 \cdot 3$ & 1 & ${ }^{*} \mathrm{R} 12 \cdot 15$ \\
\hline 1 & 3 & ${ }^{*} \mathrm{R} 36 \cdot 44$ \\
\hline 2 & 6 & ${ }^{*} \mathrm{R} 72 \cdot 88$ \\
\hline 3 & 9 & ${ }^{*} \mathrm{R} 109 \cdot 32$ \\
\hline 4 & 12 & ${ }^{*} \mathrm{R} 145 \cdot 76$ \\
\hline
\end{tabular}

Table 4 Rank-order stability analysis 


\section{Pharmacoeconomic evaluation}

The resource use associated with management of each $A E$ manifestation (such as air-in-line) is reflected in Appendix 1. Type and frequency of AEs has been identified as major cost drivers. Appendixes 2 and 3 reflects the full cost modelling which incorporate cost and frequency of occurrence.

Table 3 reflects the cost to manage a hypothetical 1000 IV-bags infused. The IVF/RC group achieves a significant wastage reduction of $76 \%$.

To determine cost-effectiveness of the IVF-device the Cost to Patient or Third party should be known. Therefore, a ROSA (rank-order stability analysis) (Einarson et al. 1995) was employed to project a break-even point (Table 4).

The ROSA indicates that if the addition of the IVF-device to STD IV-sets cost less than R12.15 a cost saving would be achieved from the first IV-bag infused. This cost-effectiveness would escalate with every additional bag infused (as reflected by increased break-even point).

\section{Discussion}

Providers must evaluate the associated costs as well as the system characteristics when deciding on a method for administration of intravenous medications. Complications associated with gravitational infusion sets impact negatively on patient care and resource utilization.

The parent study (Stargait) aimed to quantify possible superiority with regards to clinical administration and economic outcomes, of standard gravitational sets equipped with the IVF to those without IVF. This study clearly demonstrates the reduction in incidence of AEs (e.g. air in line, reverse flow, clotting, etc.) as well as the significant impact on costs. The absolute $18 \%$ reduction ( $p \leq 0.0069)$ is remarkable over the short duration of the study (55\% relative reduction), which translates into a $76 \%$ cost saving per 1000 IV-bags infused. A vaculitre in the control arm (standard/roller clamp) had a 2.2 times greater chance of an adverse event than a vaculitre in the IVF/roller clamp arm.

The superiority of the IVF group over the standard IV line in achieving an accurate flow rate has been demonstrated. The mean deviation associated with IVF (just more than $5 \mathrm{ml} / \mathrm{hour}$ ) is significantly lower than that for the standard IV-line (30 ml/hour). 


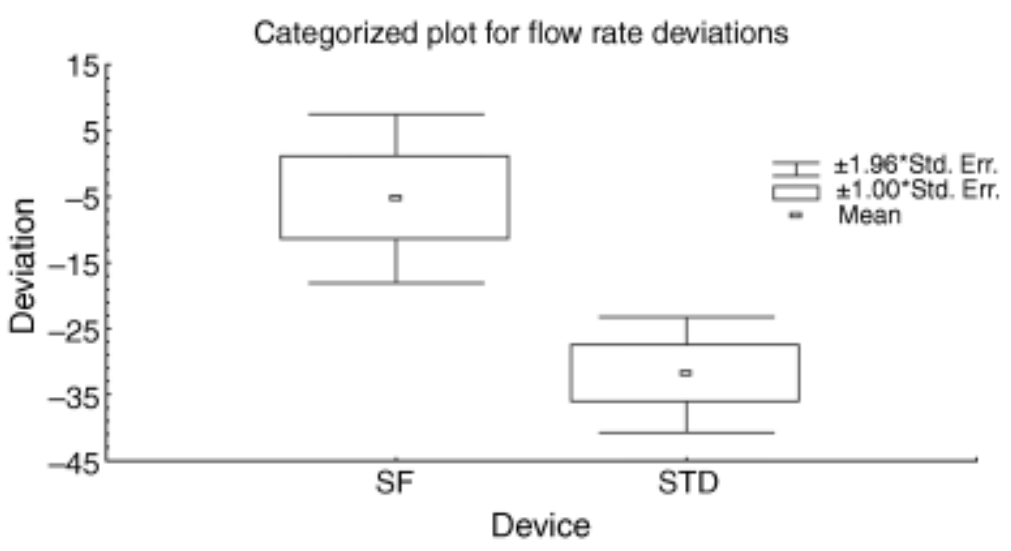

Figure 3 Box and whisker plot: the significance of the difference between the two groups of observations and the superiority of the IV ${ }^{2 \mathrm{TM}}$ flow group over the standard IV line group - as indicated by smaller mean deviations (Note: $S F=I V^{2 T M}$ flow).

The Stargait trial evaluated hard endpoints with regards to equipment (i.e. IVF vs. standard IV infusion sets) and management thereof and did not measure patient disease outcomes directly. Patient specific parameters such as volume overload, dehydration, AEs and the impact thereof on disease and length of hospital stay were not measured and forms part of a future study. It is, however, clear that a simple but effective change in how we administer intravenous fluids already makes a significant difference when we calculate nursing care costs, patient specific impact (AEs) and accuracy of fluid administration.

The impact of a flow variation of $30 \mathrm{ml} /$ hour may seem small on a hourly basis but calculated over 24 hours makes a big difference to the total volume administered. This can clearly lead to inadequate volume replacement in patients with compromised organ functions or with extensive disease such as burns where input and output measurement and administration is critical to the clinical outcome of the patient (Shafiee et al. 2004).

In environments where accurate medicine administration is mandatory, a more reliable and simple device may benefit patients, especially in more resource constrained settings.

\section{Conclusion}

The intervention in this trial, the IVF, as an add-on device in standard gravitational sets, was proven to be care- and cost-effective. The investigators support the routine implementation of the IVF-device in everyday clinical practise.

\section{Contributions}

Study design: NF, JRS, GN, FW; data collection: NF, SV, PN, DW, AV, AH, SCM, CR; analysis: $\mathrm{NF}, \mathrm{GN}, \mathrm{FW}$ and manuscript preparation: NF, GN, JRS, FW. 


\section{References}

BirdwellSW (1993) Direct costs of intravenous delivery systems. Pharmacoeconomics 4, 8-13.

EinarsonR, ArikianS\&DoyleJ (1995) Rank-order stability analysis (ROSA): testing pharmacoeconomic data. Medical Decision Making 15, 367-372.

FraserN, NeIG, SnymanJ\&WesselsF (2004) IV-EVENT Study: Intravenous Infusion TherapyManagement and Adverse Events. Data on File. Varori International (Pty) Ltd., Centurion, South Africa

KerAME (2002) Clinical Validation of the IV ${ }^{2 T M}$ flow System. Data on File. Varori International (Pty) Ltd., Centurion, South Africa

LarsonE\&HargissRN (1984) A decentralized approach to maintenance of intravenous therapy. American Journal of Infection Control 12, 177-186.

MakkinkJ (2001) The Medical Doctor's Responsibility and Decisions. Data on file. Varori International (Pty) Ltd., Centurion, South Africa

ShafieeMAS, BohnD, HoornEJ\&HalperinML (2003) How to select optimal maintenance intravenous fluid therapy. Quarterly Journal of Medicine 96, 601-610. 


\section{Appendix}

Appendix 1: Cost dictionary per manifestation

\begin{tabular}{|c|c|c|c|c|c|c|c|c|c|c|c|c|}
\hline & & & & $\begin{array}{l}\text { Air-In- } \\
\text { line }\end{array}$ & $\begin{array}{c}\text { Rev } \\
\text { blood } \\
\text { flow }\end{array}$ & $\begin{array}{c}\text { Clot } \\
\text { formed }\end{array}$ & Repriming & $\begin{array}{l}\text { Needle } \\
\text { dislodge }\end{array}$ & $\begin{array}{l}\text { Fluid in } \\
\text { tissue }\end{array}$ & Phlebitis & $\begin{array}{l}\text { Allergic } \\
\text { reaction }\end{array}$ & $\begin{array}{l}\text { Access site } \\
\text { related }\end{array}$ \\
\hline \multicolumn{13}{|c|}{ Labour costs (IV-Event) } \\
\hline \multicolumn{2}{|c|}{$\begin{array}{l}\text { Nursing staff (cost per } \\
\text { min) }\end{array}$} & & $\mathrm{R} 0 \cdot 70$ & $\mathrm{R} 5 \cdot 38$ & $\mathrm{R} 5 \cdot 38$ & $\mathrm{R} 5 \cdot 38$ & $\mathrm{R} 5 \cdot 38$ & $\mathrm{R} 5 \cdot 38$ & $\mathrm{R} 5 \cdot 38$ & $\mathrm{R} 5 \cdot 38$ & $\mathrm{R} 5 \cdot 38$ & $\mathrm{R} 5 \cdot 38$ \\
\hline \multicolumn{2}{|c|}{$\begin{array}{l}\text { Nursing staff time (min) } \\
\text { per } A E^{*}\end{array}$} & & $7 \cdot 7$ & & & & & & & & & \\
\hline \multicolumn{13}{|c|}{ Consumable costs } \\
\hline & & CODE & SEP (incl VAT) & & & & & & & & & \\
\hline \multicolumn{2}{|c|}{$\begin{array}{l}\text { Ave cost per IV-bag } \\
(1000 \mathrm{ml})\end{array}$} & & R43.89 & & & & $\mathrm{R} 2 \cdot 98$ & $\mathrm{R} 2 \cdot 98$ & $\mathrm{R} 2 \cdot 98$ & $\mathrm{R} 2.98$ & $\mathrm{R} 2 \cdot 98$ & $\mathrm{R} 2 \cdot 98$ \\
\hline \multicolumn{2}{|l|}{ Wastage* $\left.^{*} \%\right)$} & & $6 \cdot 8 \%$ & & & & & & & & & \\
\hline Syringes & $5 \mathrm{ml}$ & 232 & $\mathrm{R} 6 \cdot 88$ & $\mathrm{R} 6 \cdot 88$ & $\mathrm{R} 6 \cdot 88$ & $\mathrm{R} 6 \cdot 88$ & & & & & & \\
\hline Needles & & 249 & $\mathrm{R} 1 \cdot 75$ & $\mathrm{R} 1 \cdot 75$ & $\mathrm{R} 1 \cdot 75$ & $\mathrm{R} 1 \cdot 75$ & & & & & & \\
\hline Webcol & & 252 & $\mathrm{R} 0.49$ & R0.49 & $\mathrm{R} 0 \cdot 49$ & $\mathrm{R} 0 \cdot 49$ & $\mathrm{R} 0 \cdot 49$ & $\mathrm{R} 0.49$ & $\mathrm{R} 0 \cdot 49$ & $\mathrm{R} 0 \cdot 49$ & R0.49 & $\mathrm{R} 0.49$ \\
\hline $\begin{array}{l}\text { Gloves } \\
\text { examination }\end{array}$ & & 712 & $\mathrm{R} 1 \cdot 80$ & & & & $\mathrm{R} 1 \cdot 80$ & $\mathrm{R} 1 \cdot 80$ & $\mathrm{R} 1 \cdot 80$ & $\mathrm{R} 1 \cdot 80$ & $\mathrm{R} 1 \cdot 80$ & $\mathrm{R} 1 \cdot 80$ \\
\hline Linen saver & & 889 & $\mathrm{R} 1 \cdot 43$ & & & & $\mathrm{R} 1 \cdot 43$ & $\mathrm{R} 1 \cdot 43$ & $\mathrm{R} 1 \cdot 43$ & $\mathrm{R} 1 \cdot 43$ & $\mathrm{R} 1 \cdot 43$ & $\mathrm{R} 1 \cdot 43$ \\
\hline IV-tray & & 631 & R15.00 & & & & R15.00 & R15.00 & R15.00 & R15.00 & R15.00 & R15.00 \\
\hline Jelco & & 283 & $\mathrm{R} 60 \cdot 77$ & & & & $\mathrm{R} 60 \cdot 77$ & $\mathrm{R} 60 \cdot 77$ & $\mathrm{R} 60 \cdot 77$ & R60.77 & $\mathrm{R} 60 \cdot 77$ & $\mathrm{R} 60 \cdot 77$ \\
\hline Tegaderm & 1626 & 463 & $\mathrm{R} 29 \cdot 43$ & & & & $\mathrm{R} 29 \cdot 43$ & $\mathrm{R} 29 \cdot 43$ & $\mathrm{R} 29 \cdot 43$ & $\mathrm{R} 29 \cdot 43$ & $\mathrm{R} 29 \cdot 43$ & $\mathrm{R} 29 \cdot 43$ \\
\hline \multirow[t]{2}{*}{ Water } & $5 \mathrm{ml}$ & 28 & $\mathrm{R} 5 \cdot 24$ & & & $\mathrm{R} 5 \cdot 24$ & & & & & & \\
\hline & & & $\begin{array}{l}\text { Cost per } \\
\text { manifestation }\end{array}$ & $\mathrm{R} 14 \cdot 50$ & $\mathrm{R} 14 \cdot 50$ & R19.74 & $\mathrm{R} 117 \cdot 28$ & $\mathrm{R} 117 \cdot 28$ & $\mathrm{R} 117 \cdot 28$ & $\mathrm{R} 117 \cdot 28$ & $\mathrm{R} 117 \cdot 28$ & $\mathrm{R} 117 \cdot 28$ \\
\hline \multicolumn{13}{|c|}{ *As per IV-Event Study } \\
\hline
\end{tabular}


Appendix 2: AE and manifestation schedule - STD/RC

\begin{tabular}{|c|c|c|c|c|c|c|c|c|c|c|c|c|}
\hline & $\begin{array}{l}\text { Air-In- } \\
\text { line }\end{array}$ & $\begin{array}{l}\text { Rev } \\
\text { blood } \\
\text { flow }\end{array}$ & $\begin{array}{l}\text { Clot } \\
\text { formed }\end{array}$ & Repriming & $\begin{array}{l}\text { Needle } \\
\text { dislodge }\end{array}$ & $\begin{array}{l}\text { Access } \\
\text { site } \\
\text { related }\end{array}$ & $\begin{array}{l}\text { Fluid in } \\
\text { tissue }\end{array}$ & $\begin{array}{c}\text { Reverse } \\
\text { blood + clot }\end{array}$ & $\begin{array}{l}\text { Reverse + } \\
\text { fluid }\end{array}$ & $\begin{array}{l}\text { Reprime }+ \text { fluid }+ \\
\text { allergic reaction }\end{array}$ & $\begin{array}{l}\text { Number of } \\
\text { manifest }\end{array}$ & $\begin{array}{l}\text { Number } \\
\text { of } 1000\end{array}$ \\
\hline $\begin{array}{l}\text { Number of bags in } \\
\text { study arm }\end{array}$ & & & & & & & & & & & 68 & $34 \%$ \\
\hline $\begin{array}{l}\text { Number of patients } \\
\text { with } A E\end{array}$ & & & & & & & & & & & 11 & \\
\hline $\begin{array}{l}\text { Number of bags } \\
\text { with } A E\end{array}$ & & & & & & & & & & & 20 & \\
\hline Number of AE's & & & & & & & & & & & 23 & 338 \\
\hline $\begin{array}{l}\text { Number of } \\
\text { manifestations }\end{array}$ & 8 & 4 & 3 & 2 & & & 3 & 1 & 1 & 1 & 27 & R15 939 \\
\hline \multicolumn{13}{|l|}{ Labour costs } \\
\hline $\begin{array}{l}\text { Nursing staff (cost } \\
\text { per min) }\end{array}$ & $\mathrm{R} 5 \cdot 38$ & $\mathrm{R} 5 \cdot 38$ & $\mathrm{R} 5 \cdot 38$ & $\mathrm{R} 5 \cdot 38$ & $\mathrm{R} 5 \cdot 38$ & $\mathrm{R} 5 \cdot 38$ & $\mathrm{R} 5 \cdot 38$ & $\mathrm{R} 5 \cdot 38$ & $\mathrm{R} 5 \cdot 38$ & $\mathrm{R} 5 \cdot 38$ & & \\
\hline \multicolumn{13}{|l|}{ Consumable costs } \\
\hline Wastage (\%) & $7 \cdot 8 \%$ & & & $\mathrm{R} 3 \cdot 41$ & $\mathrm{R} 3 \cdot 41$ & $\mathrm{R} 3 \cdot 41$ & R3.41 & $\mathrm{R} 3 \cdot 41$ & $\mathrm{R} 3 \cdot 41$ & $\mathrm{R} 3 \cdot 41$ & & \\
\hline Syringes & $\mathrm{R} 6 \cdot 88$ & $\mathrm{R} 6 \cdot 88$ & $\mathrm{R} 6 \cdot 88$ & & & & & $\mathrm{R} 6 \cdot 88$ & $\mathrm{R} 6 \cdot 88$ & & & \\
\hline Needles & $\mathrm{R} 1 \cdot 75$ & $\mathrm{R} 1 \cdot 75$ & $\mathrm{R} 1 \cdot 75$ & & & & & $\mathrm{R} 1 \cdot 75$ & $\mathrm{R} 1 \cdot 75$ & & & \\
\hline Webcol & $\mathrm{R} 0 \cdot 49$ & $\mathrm{R} 0 \cdot 49$ & $\mathrm{R} 0 \cdot 49$ & $\mathrm{R} 0 \cdot 49$ & $\mathrm{R} 0 \cdot 49$ & $\mathrm{R} 0 \cdot 49$ & $\mathrm{R} 0 \cdot 49$ & $\mathrm{R} 0 \cdot 49$ & $\mathrm{R} 0 \cdot 49$ & $\mathrm{R} 0 \cdot 49$ & & \\
\hline Gloves examination & & & & $\mathrm{R} 1 \cdot 80$ & $\mathrm{R} 1 \cdot 80$ & $\mathrm{R} 1 \cdot 80$ & $\mathrm{R} 1 \cdot 80$ & & $\mathrm{R} 1 \cdot 80$ & $\mathrm{R} 1 \cdot 80$ & & \\
\hline Linen saver & & & & $\mathrm{R} 1 \cdot 43$ & $\mathrm{R} 1 \cdot 43$ & $\mathrm{R} 1 \cdot 43$ & $\mathrm{R} 1 \cdot 43$ & & $\mathrm{R} 1 \cdot 43$ & $\mathrm{R} 1 \cdot 43$ & & \\
\hline IV-tray & & & & R15.00 & R15.00 & R15.00 & R15.00 & & R15.00 & R15.00 & & \\
\hline Jelco & & & & $\mathrm{R} 60 \cdot 77$ & $\mathrm{R} 60 \cdot 77$ & $\mathrm{R} 60 \cdot 77$ & R60.77 & & $\mathrm{R} 60 \cdot 77$ & $\mathrm{R} 60 \cdot 77$ & & \\
\hline Tegaderm & & & & R29.43 & R29.43 & R29.43 & R29.43 & & $\mathrm{R} 29 \cdot 43$ & R29.43 & & \\
\hline Water & & & $\mathrm{R} 5 \cdot 24$ & & & & & $\mathrm{R} 5 \cdot 24$ & & & & \\
\hline $\begin{array}{l}\text { Cost per } \\
\text { manifestation }\end{array}$ & R14.50 & $R 14 \cdot 50$ & R19.74 & $\mathrm{R} 117 \cdot 28$ & $\mathrm{R} 117 \cdot 71$ & $\mathrm{R} 117 \cdot 71$ & $\mathrm{R} 117 \cdot 71$ & R17.91 & R127.34 & $\mathrm{R} 117 \cdot 71$ & & \\
\hline $\begin{array}{l}\text { Total cost } \\
\text { of manifestations }\end{array}$ & R115.98 & R57.99 & R59.21 & $\mathrm{R} 234.56$ & $\mathrm{R} 0 \cdot 00$ & $\mathrm{R} 0 \cdot 00$ & R353.14 & R17.91 & $\mathrm{R} 127 \cdot 34$ & $\mathrm{R} 117 \cdot 71$ & R1084 & \\
\hline \multirow[t]{3}{*}{ Ave cost per AE } & & & & & & & & & & & $\mathrm{R} 47 \cdot 12$ & \\
\hline & R43.02 & R21.51 & $\mathrm{R} 16 \cdot 13$ & $\mathrm{R} 10 \cdot 75$ & - & - & R16.13 & $\mathrm{R} 5 \cdot 38$ & $\mathrm{R} 5 \cdot 38$ & $\mathrm{R} 5 \cdot 38$ & $\mathrm{R} 123 \cdot 67$ & $11 \cdot 4 \%$ \\
\hline & & & & & & & & & & & $\mathrm{R} 5 \cdot 38$ & \\
\hline
\end{tabular}


Appendix 3: AE and manifestation schedule - IVF/RC

\begin{tabular}{|c|c|c|c|c|c|c|c|c|c|}
\hline & $\begin{array}{l}\text { Air-In- } \\
\text { line }\end{array}$ & $\begin{array}{l}\text { Rev blood } \\
\text { flow }\end{array}$ & $\begin{array}{l}\text { Clot } \\
\text { formed }\end{array}$ & Repriming & $\begin{array}{l}\text { Needle } \\
\text { dislodge }\end{array}$ & $\begin{array}{l}\text { Access site } \\
\text { related }\end{array}$ & $\begin{array}{l}\text { Reprime }+ \\
\text { fluid }\end{array}$ & $\begin{array}{c}\text { Number of } \\
\text { manifest }\end{array}$ & $\begin{array}{c}\text { Number of } \\
1000\end{array}$ \\
\hline $\begin{array}{l}\text { Number of Bags in study } \\
\text { arm }\end{array}$ & & & & & & & & 78 & \\
\hline $\begin{array}{l}\text { Number of Patients with } \\
A E\end{array}$ & & & & & & & & 8 & \\
\hline Number of Bags with $A E$ & & & & & & & & 9 & $15 \cdot 4 \%$ \\
\hline Number of $A E$ 's & & & & & & & & 12 & 154 \\
\hline $\begin{array}{l}\text { Number of } \\
\text { Manifestations }\end{array}$ & 5 & 2 & 4 & & & & 1 & 13 & R3 792.01 \\
\hline \multicolumn{10}{|l|}{ Labour costs } \\
\hline $\begin{array}{l}\text { Nursing staff (cost per } \\
\text { min) }\end{array}$ & $\mathrm{R} 5 \cdot 38$ & $\mathrm{R} 5 \cdot 38$ & $\mathrm{R} 5 \cdot 38$ & $\mathrm{R} 5 \cdot 38$ & $\mathrm{R} 5 \cdot 38$ & $\mathrm{R} 5 \cdot 38$ & R5.38 & & \\
\hline \multicolumn{10}{|l|}{ Consumable costs } \\
\hline $\begin{array}{l}\text { Fluid wastage (\%) } \\
(1000 \mathrm{ml})\end{array}$ & $2 \cdot 4 \%$ & & & $\mathrm{R} 2 \cdot 98$ & $\mathrm{R} 2 \cdot 98$ & $\mathrm{R} 2 \cdot 98$ & R1.05 & & \\
\hline Syringes & $\mathrm{R} 6 \cdot 88$ & $\mathrm{R} 6 \cdot 88$ & $\mathrm{R} 6 \cdot 88$ & & & & & & \\
\hline Needles & $\mathrm{R} 1 \cdot 75$ & $\mathrm{R} 1 \cdot 75$ & $\mathrm{R} 1 \cdot 75$ & & & & & & \\
\hline Webcol & R0.49 & R0.49 & R0.49 & R0.49 & $\mathrm{R} 0 \cdot 49$ & R0.49 & R0.49 & & \\
\hline Gloves examination & & & & $\mathrm{R} 1 \cdot 80$ & $\mathrm{R} 1 \cdot 80$ & $\mathrm{R} 1 \cdot 80$ & $\mathrm{R} 1 \cdot 80$ & & \\
\hline Linen saver & & & & $\mathrm{R} 1 \cdot 43$ & $\mathrm{R} 1 \cdot 43$ & $\mathrm{R} 1 \cdot 43$ & $\mathrm{R} 1 \cdot 43$ & & \\
\hline IV-tray & & & & R15.00 & R15.00 & R15.00 & R15.00 & & \\
\hline Jelco & & & & $\mathrm{R} 60 \cdot 77$ & $\mathrm{R} 60 \cdot 77$ & R60.77 & R60.77 & & \\
\hline Tegaderm & & & & $\mathrm{R} 29 \cdot 43$ & $\mathrm{R} 29 \cdot 43$ & $\mathrm{R} 29 \cdot 43$ & $\mathrm{R} 29 \cdot 43$ & & \\
\hline Water & & & $\mathrm{R} 5 \cdot 24$ & & & & & & \\
\hline Cost per manifestation & $\mathrm{R} 14 \cdot 50$ & R14.50 & R19.74 & $\mathrm{R} 117 \cdot 28$ & $\mathrm{R} 117 \cdot 28$ & $\mathrm{R} 117 \cdot 28$ & R115.35 & & \\
\hline $\begin{array}{l}\text { Total cost of } \\
\text { manifestations }\end{array}$ & $\mathrm{R} 72 \cdot 49$ & R28.99 & R78.95 & R0.00 & Ro.00 & Ro.00 & $\mathrm{R} 115 \cdot 35$ & R296 & \\
\hline \multirow[t]{3}{*}{ Ave cost per $A E$} & & & & & & & & R24.65 & \\
\hline & R26.89 & R10.75 & R21.51 & - & - & - & R5.38 & R64.53 & $21 \cdot 8 \%$ \\
\hline & & & & & & & & R5.38 & \\
\hline
\end{tabular}

